\title{
Semi-Autonomous Cooperative Driving for Mobile Robotic Telepresence Systems
}

\author{
Andrey Kiselev \\ Örebro University \\ 70182 Örebro, Sweden \\ andrey.kiselev@ oru.se
}

\author{
Giovanni Mosiello \\ Roma Tre University \\ Via Ostiense 159, 00154 \\ Rome, Italy \\ gio.mosiello@gmail.com \\ Amy Loutfi \\ Örebro University \\ 70182 Örebro, Sweden \\ amy.loutfi@oru.se
}

\author{
Annica Kristoffersson \\ Örebro University \\ 70182 Örebro, Sweden \\ annica.kristoffersson@oru.se
}

\section{Categories and Subject Descriptors}

I.2.9 [Robotics]: Commercial robots and applications; H.5.2

[User interfaces]: Graphical user interfaces (GUI)

\section{Keywords}

Human-Robot Interaction, Mobile Robotic Telepresence, Teleoperation, User Interfaces

\begin{abstract}
Mobile robotic telepresence (MRP) has been introduced to allow communication from remote locations. Modern MRP systems offer rich capabilities for human-human interactions. However, simply driving a telepresence robot can become a burden especially for novice users, leaving no room for interaction at all. In this video we introduce a project which aims to incorporate advanced robotic algorithms into manned telepresence robots in a natural way to allow human-robot cooperation for safe driving. It also shows a very first implementation of cooperative driving based on extracting a safe drivable area in real time using the image stream received from the robot.
\end{abstract}

\footnotetext{
Permission to make digital or hard copies of part or all of this work for personal or classroom use is granted without fee provided that copies are not made or distributed for profit or commercial advantage, and that copies bear this notice and the full citation on the first page. Copyrights for third-party components of this work must be honored. For all other uses, contact the owner/author(s). Copyright is held by the author/owner(s).

HRI'14, March 3-6, 2014, Bielefeld, Germany.

ACM 978-1-4503-2658-2/14/03.

http://dx.doi.org/10.1145/2559636.2559640.
} 